ABSTRACT: Single thenar motor unit $F$ waves (FMUPs) were collected from 23 healthy volunteers (age range 21-91 years, mean $46 \pm 20 \mathrm{SD}$ ). In each subject, 10 distinct FMUPs were recorded, using surface stimulating and recording electrodes, and the conduction velocity (CV) of each motor unit was calculated. The distribution of CVs (overall range $42-66 \mathrm{~m} / \mathrm{s}$; individual FMUP CV dispersion range 6-27\% of the maximal FMUP CV) was close to those previously reported whatever the technique used. With age, a progressive CV reduction was observed, and maximal FMUP CV was significantly correlated with age $(r=-0.58, P<0.01)$, whereas no statistically significant correlation was found between minimal FMUP CV and age $(r=$ $-0.27, \mathrm{~ns})$. Individual FMUP CV dispersion presented a statistically significant decrease with age $(r=-0.46, P<0.05)$. Furthermore, thenar motor unit number (MUNE), estimated by the adapted multiple point stimulation method, decreased progressively with age and was statistically correlated with maximal FMUP CV $(r=0.59, P<0.01)$, whereas there was no correlation with minimal FMUP CV $(r=0.34$, ns). Thus, we propose that motor unit loss is progressive with age throughout life, affecting particularly the largest and fastest conducting motor units. Preferential involvement of these fibers could be responsible for the age-related changes in motor nerve CV.

(C) 1999 John Wiley \& Sons, Inc. Muscle Nerve 22: 1022-1029, 1999

\title{
AGE-RELATED CHANGES IN FASTEST AND SLOWEST CONDUCTING AXONS OF THENAR MOTOR UNITS
}

\author{
FRANÇOIS-CHARLES WANG, MD, VICTOR DE PASQUA, and \\ PAUL J. DELWAIDE, MD, PhD
}

University Department of Neurology, Hôpital de la Citadelle, Bld du 12 ème de Ligne 1,

B-4000 Liège, Belgium

Accepted 10 March 1999

A progressive decrease with aging in motor conduction velocities (CVs) has been previously reported in several studies. ${ }^{21,47,50}$ However, these data relate only to the fastest conducting motor units (maximal CV). More recently, Arasaki et al. ${ }^{2}$ and Doherty et al. ${ }^{20}$ described uniform slowing of motor axon CVs of both fast-conducting and slow-conducting nerve fibers with age. The cause of such a reduction in motor CVs of all nerve fibers with aging may be a reduction in axonal diameters ${ }^{45}$ or internodal length; for example, those induced by demyelination-remyelination. ${ }^{3,22,33,41}$ However, the major age-related quantitative change in peripheral nerves appears to be a decrease in myelinated fiber number

Abbreviations: AMPS, adapted multiple point stimulation; CV, conduction velocity; FMUP, single motor unit F wave; MUNE, motor unit number estimate; SFEMG, single-fiber electromyography; S-MUAP, surfacerecorded motor unit action potentials

Key words: single motor unit F-wave (FMUP); thenar muscles; motor unit number estimate (MUNE); conduction velocity (CV); surface-recorded motor unit action potential (S-MUAP)

Correspondence to: P. J. Delwaide

CCC 0148-639X/99/081022-08

(C) 1999 John Wiley \& Sons, Inc. with advancing age. ${ }^{54,56}$ This cannot explain the uniform slowing of conduction in fast and slow motor units with age. Indeed, random myelinated fiber loss should result in decreased maximal CV by disappearance of the fastest conducting motor units and an increase in minimal CV due to disappearance of the slowest conducting motor units. By contrast, if myelinated fiber loss predominates either in the largeor small-diameter group, there should be a prominent slowing of maximal CV or a prominent increase in minimal $\mathrm{CV}$, respectively.

Myelinated fiber loss may be analyzed anatomically or electrophysiologically by motor unit number estimate (MUNE) techniques. The decline in motor unit number with age has been studied extensively. It remains unclear, however, whether there is a decline in number of motor units starting after the age of 60 years ${ }^{15,44,53,55}$ or a continuous depletion of motor units throughout life, ${ }^{7,9,36,45,58,60,61}$ which, if motor unit loss and age-related CV changes are correlated, would better explain the progressive $\mathrm{CV}$ slowing with age. 
In the present study, we measured, in 23 healthy subjects, both thenar MUNEs, using the adapted multiple point stimulation (AMPS) method, ${ }^{58}$ and peripheral motor CVs of slow and fast thenar motor units by recording single motor unit $\mathrm{F}$ waves (FMUPs). Our aim was to test the following hypotheses: (a) the decline in MUNEs is progressive throughout adult life; (b) motor unit loss with age is one prominent mechanism responsible for the agerelated changes in the peripheral motor nerve CV; and (c) there is a preferential degeneration of the largest and fastest motor units.

\section{METHODS}

Subjects. Data were collected from 23 volunteers (16 women and 7 men), after we had obtained their informed consent. Their ages ranged from 21 to 91 years (mean $46 \pm 20 \mathrm{SD}$ ). Each subject's medical history was reviewed and a standardized neurological examination was performed. None of our subjects reported symptoms or had neurological abnormalities on examination that were suggestive of peripheral nerve disease. None had symptoms or signs of a metabolic disorder such as diabetes or renal failure. We excluded carpal tunnel entrapment neuropathy by clinical examination and electrophysiological tests (motor conduction velocity with terminal latency index and palmar stimulation of sensory fibers). No one presented with hypo- or hyperreflexia. Subjects with any health problem were excluded from the group. Subjects were not screened by needle examination for possible subclinical C-8 radiculopathy.

Single Motor Unit F-Wave Recording System. All studies were performed on a Nicolet Viking I EMG machine (Nicolet, Madison, WI). FMUPs were evoked by 0.05 -ms constant-current square waves repeated at $1 \mathrm{~Hz}$. Successive submaximal stimuli, with intensities that orthodromically evoke one (Fig. 1) or only a few thenar motor units, were delivered to the median nerve at the wrist and the resultant late responses were compared. Late responses identical in shape, size, and latency on two or more occasions were attributed to recurrent responses of a single motor unit (F response) (Fig. 1). As indicated by Chroni and Panayiotopoulos, ${ }^{17}$ this single criterion, which assumes that FMUPs are representative of single motor units, cannot eliminate repeated combination of two or more motor units in the $\mathrm{F}$ response. However, the chance of combinations of two or more motor units repeating a sufficient number of times to be counted as a single S-MUAP is very small in healthy subjects (about once in 1000 trials, if

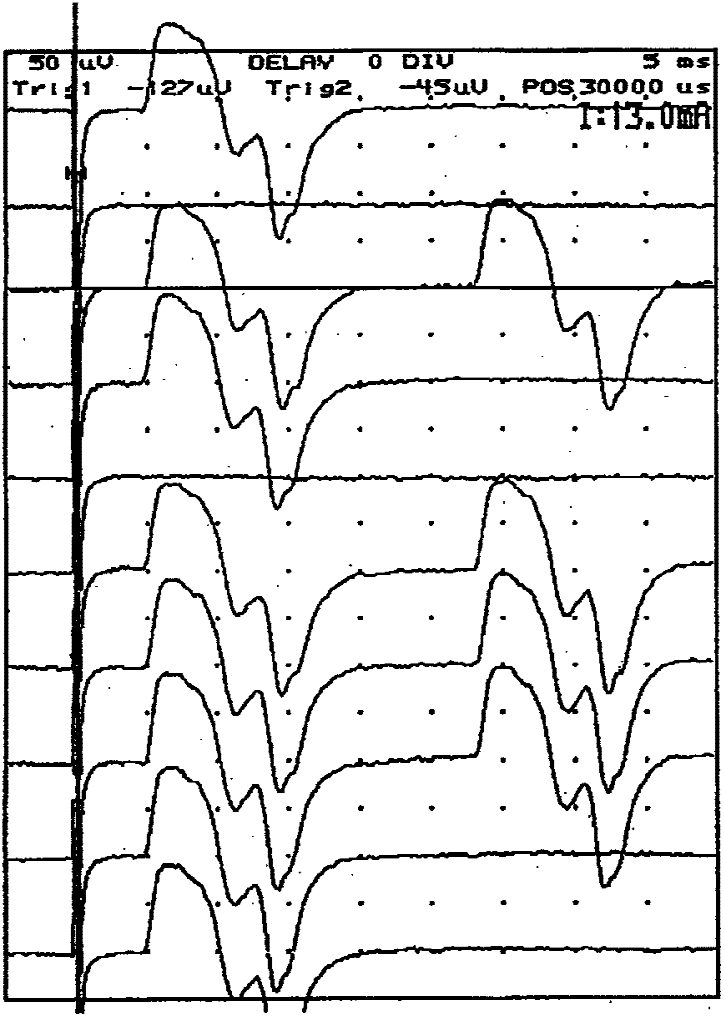

FIGURE 1. Single thenar motor unit $F$ waves evoked by nearthreshold stimulation in a healthy subject. Identical shape and size of early and late motor responses, with all-or-nothing elicitation, indicates that only one motor unit was involved in these responses.

$\mathrm{F}$ persistence is $1-3 \%) .{ }^{10,20}$ Certainty regarding $\mathrm{F}$ wave representation of a single motor unit could be increased by requiring recurrences of three rather than two $\mathrm{F}$ responses, but the method would then become too time-consuming.

FMUPs were recorded (bandpass $10 \mathrm{~Hz}$ to $5 \mathrm{kHz}$ ) with a gain of 50-100 $\mu \mathrm{V} /$ division by using surface electrodes (silver foil, $6 \mathrm{~cm}$ long and $0.8 \mathrm{~cm}$ wide). The stigmatic electrode was positioned transversely over the thenar eminence as close as possible to the muscle endplates. The reference electrode was attached over the proximal phalanx of the thumb. The ground electrode was fixed over the dorsum of the wrist.

From each subject, 10 distinct FMUPs were collected. Sometimes one single stimulation point was not enough for us to obtain 10 distinct motor responses. In such a case, the cathode was moved to alternative sites over the nerve trunk.

During data collection, subjects remained completely relaxed and no additional facilitation was used to increase F-response persistence. In this manner, we minimized the risk of FMUP contamination 
by $\mathrm{H}$ reflexes. Indeed, in healthy subjects at rest, an $\mathrm{H}$ reflex is rarely evoked in the intrinsic hand muscles. ${ }^{34,59}$ Moreover, the use of 0.05-ms-duration stimuli did not favor Hov-reflex elicitation. ${ }^{49}$

Conduction Velocity Calculation. In each subject, CVs of 10 distinct FMUPs were calculated using the following equation (adapted from Kimura ${ }^{37}$ ):

$$
\text { FMUP CV }=\frac{2 \times \text { distance from stimulus site to } \mathrm{C}-7}{\text { F latency }-(\mathrm{MTL}+1 \mathrm{~ms})}
$$

where MTL represents the motor terminal latency of the direct motor response and $1 \mathrm{~ms}$ the central turnaround delay for the $\mathrm{F}$ response. ${ }^{24}$

From the 10 evoked FMUPs in each subject, maximal and minimal CVs were selected and considered to be representative of the fastest and slowest motor unit CVs, respectively.

Thenar MUNE Method. The number of thenar motor units was estimated by the AMPS technique. This method, with its advantages and its reliability, has been presented in detail in a previous study. ${ }^{58} \mathrm{We}$ preferred AMPS to the F-response technique for two reasons: (1) the F-response technique ${ }^{25}$ does not take into account the phase cancellation that occurs in maximal $\mathrm{M}$ responses; and (2) it is sometimes difficult to measure the sizes of the smaller surfacerecorded motor unit action potentials (S-MUAPs) accurately.

Statistical Analysis. Mean values have been expressed with their standard deviations and correlations calculated with regression analysis. Comparisons between maximal and minimal CVs, and relations with age or MUNE, have been made by covariance analysis.

\section{RESULTS}

Conduction Velocity Data. In each of the 23 subjects, CVs of 10 distinct FMUPs were calculated. The mean of all these values was $52.8 \pm 4 \mathrm{~m} / \mathrm{s}$ (Table 1 ), with an overall CV range of 42-66 m/s (Tables 1 and 2 ). From the 10 FMUP CVs calculated in each subject, the maximal and minimal CVs were selected. The mean maximal FMUP CV in the 23 subjects was $55.9 \pm 3.8 \mathrm{~m} / \mathrm{s}$ (range 48-66) and the mean minimal FMUP CV was $48.6 \pm 3.2 \mathrm{~m} / \mathrm{s}$ (range 42-53) (Table 1).

Figure 2 shows a statistically significant negative correlation between all the individual FMUP CVs and age $(r=-0.48, P<0.001)$, reflecting a statistically significant motor CV decrease with aging.

\begin{tabular}{|c|c|c|}
\hline \multicolumn{3}{|c|}{$\begin{array}{c}\text { Table 1. Single thenar motor unit } F \text { waves in } 23 \\
\text { control subjects. }\end{array}$} \\
\hline Variable & Mean \pm SD & Range \\
\hline FMUP CV* (m/s) & $52.8 \pm 4$ & $42-66$ \\
\hline $\begin{array}{l}\text { Maximal FMUP CV } \\
(\mathrm{m} / \mathrm{s}) \\
\text { Minimal FMUP CV }\end{array}$ & $55.9 \pm 3.8$ & $48-66$ \\
\hline $\begin{array}{l}\text { (m/s) } \\
\text { Individual FMUP CV }\end{array}$ & $48.6 \pm 3.2$ & $42-53$ \\
\hline $\begin{array}{l}\text { dispersion }(\mathrm{m} / \mathrm{s}) \\
\text { Individual FMUP CV }\end{array}$ & $7.3 \pm 3.8$ & $2.5-17.6$ \\
\hline dispersion (\%) & $13 \pm 6$ & $6-27$ \\
\hline $\begin{array}{l}\text { Thenar motor unit } \\
\text { number estimate }\end{array}$ & $284 \pm 127$ & $24-544$ \\
\hline
\end{tabular}

${ }^{*} F M U P$ CV: single motor unit F-wave conduction velocity.

tMaximal FMUP CV: the fastest conduction velocity measured in each subject.

$\ddagger$ Minimal FMUP CV: the slowest conduction velocity measured in each subject.

When considering maximal and minimal CVs separately (Fig. 3A), there was a statistically significant negative correlation between maximal FMUP $\mathrm{CV}$ and age $(r=-0.58, P<0.001)$, whereas minimal FMUP CV and age were not statistically correlated $(r$ $=-0.27, \mathrm{~ns})$. Comparison, by covariance analysis, between maximal and minimal FMUP CV and age, indicated a statistically significant difference between both regression analysis curves. However, there was only a statistical tendency for their slopes to be different $(P<0.1)$.

The mean individual FMUP CV dispersion (Ftacheodispersion ${ }^{16}$ in the 23 subjects was $7.3 \pm 3.8$ $\mathrm{m} / \mathrm{s}$ (range $2.5-17.6 \mathrm{~m} / \mathrm{s}$ ) or $13 \pm 6 \%$ of the maximal FMUP CV (range 6-27\%) (Tables 1 and 2). Individual FMUP CV dispersion showed a statistically significant decrease with age $(r=-0.46, P<0.05)$ (Fig. 4).

Number of Motor Units. The mean thenar MUNE in the 23 subjects was $284 \pm 127$ motor units (range 24-544) (Table 1). The relationship between thenar MUNE and age was analyzed by choosing the best curve-fit coefficient between linear, exponential, logarithmic, power, and polynomial 2-6 regression curves. As shown in Figure 5A, there was a statistically significant exponential decrease of MUNE with aging $(r=-0.78, P<0.001)$, reflecting a progressive loss of motor units throughout adult life. From the predicted values, the calculated mean loss of motor units was $80 \%$ between 20 and 90 years.

Relationship between FMUP CV and MUNE. Figure $6 \mathrm{~A}$ shows that there was a statistically significant correlation between maximal FMUP CV and thenar MUNE $(r=0.59, P<0.01)$, but minimal FMUP CV 
Table 2. Comparison of conduction velocity distribution studies of median motor nerve fibers.

\begin{tabular}{|c|c|c|c|}
\hline \multirow[b]{2}{*}{ Investigators } & \multicolumn{2}{|c|}{ Conduction velocity distribution } & \multirow[b]{2}{*}{ Method } \\
\hline & Overall range $(\mathrm{m} / \mathrm{s})$ & Individual range (\%) & \\
\hline Lee et al. $(1975)^{42}$ & $43-60$ & & Computer-based collision \\
\hline Ingram et al. $(1987)^{32}$ & $44-65$ & $7-23$ & $\begin{array}{l}\text { Computer-based collision } \\
\text { Voluntary activation + electrical } \\
\text { stimulation + needle electrode } \\
\text { detection of S-MUAPs }\end{array}$ \\
\hline Doherty et al. $(1994)^{20}$ & Young: 48-68; older: 39-61 & $8-20$ & FMUP method \\
\hline Wang and Delwaide (the present study) & $42-66$ & $6-27$ & FMUP method \\
\hline
\end{tabular}

and MUNE were not statistically correlated $(r=0.34$, ns). Comparison, by covariance analysis, between maximal and minimal FMUP CV related to the thenar MUNE indicated a statistically significant difference between both regression analysis curves. However, there was only a statistical tendency for their slopes to be different $(P<0.1)$.

Results in the 19 Subjects Less Than 60 Years of Age.

When the 4 oldest subjects were removed from the study, relationships between age and conduction velocity (Fig. 3B), between age and MUNE (Fig. 5B), and between MUNE and conduction velocity (Fig. 6B) were similar to previous ones.

There was a statistically significant negative correlation between maximal FMUP CV and age $(r=$ $-0.48, P<0.05)$ and there was no significant change in the rate of maximal CV decline. Minimal FMUP CV and age were not statistically correlated $(r=0.15$, ns) (Fig. 3B).

There was a statistically significant exponential decrease of MUNE with aging $(r=-0.46, P<0.05)$ (Fig. 5B); however, the curve slope of this correla-

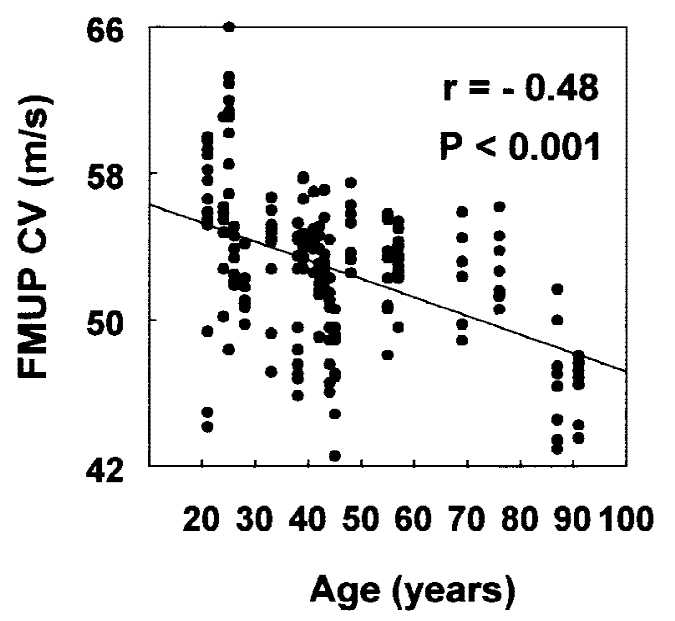

FIGURE 2. Relationship between all the individual single thenar motor unit F-wave conduction velocities (FMUP CVs) and age in 23 healthy subjects. tion was less steep. In fact, the mean loss of motor units between 20 and 90 years, calculated from the predicted values, was $60 \%$, instead of $80 \%$ in the whole group of 23 subjects.

There was a statistically significant correlation be-

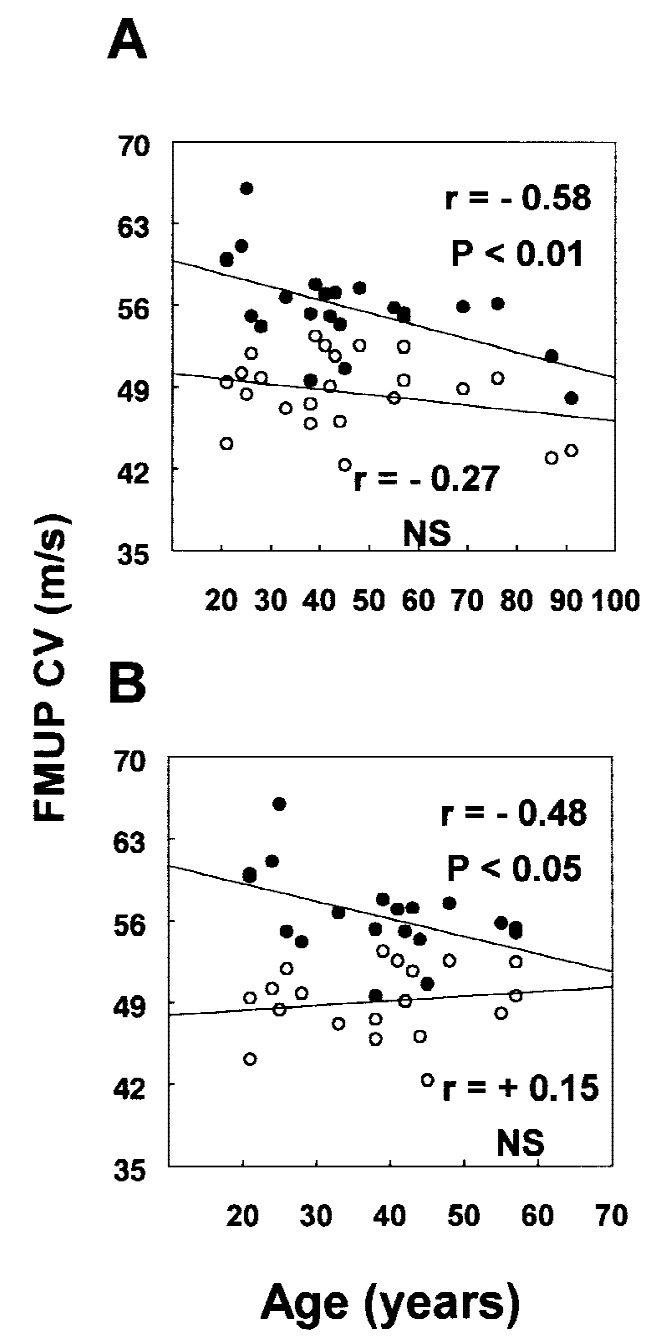

FIGURE 3. Relationship between maximal (dots) and minimal (circles) single thenar motor unit $\mathrm{F}$-wave conduction velocities (FMUP CVs) and age in: 23 healthy subjects (A); and in the 19 subjects younger than 60 years (B). 


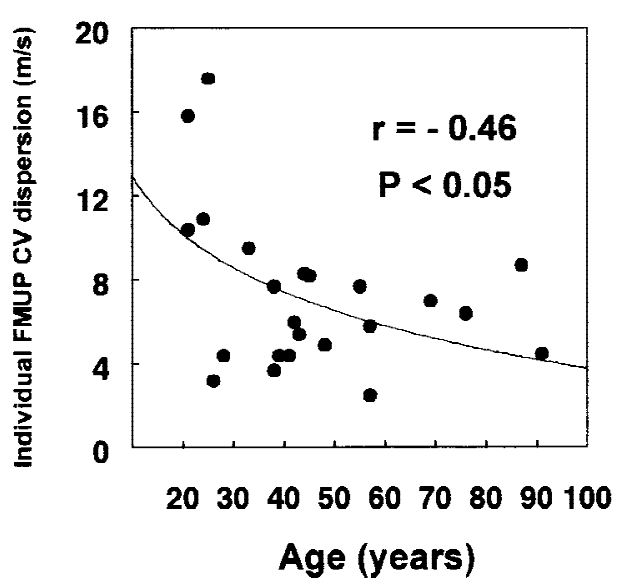

FIGURE 4. Relationship between individual single thenar motor unit F-wave conduction velocity (FMUP CV) dispersion and age in 23 healthy subjects.

tween maximal FMUP CV and thenar MUNE $(r=0.43, P<0.05)$, but minimal FMUP CV and MUNE were not statistically correlated $(r=-0.17, \mathrm{~ns})$ (Fig. 6B).

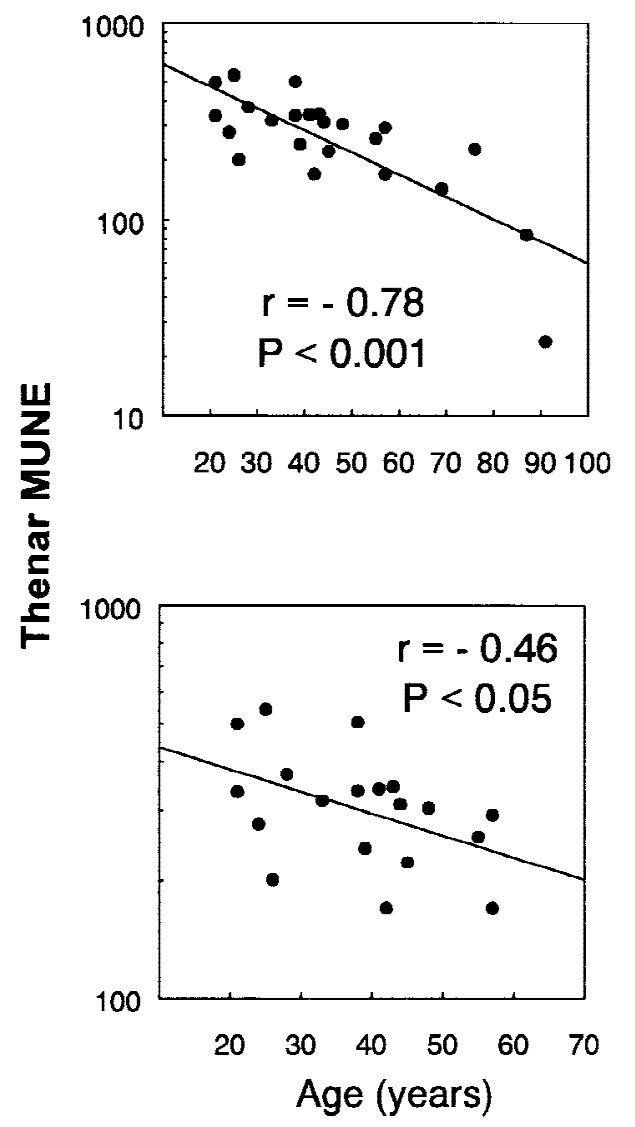

FIGURE 5. Relationship between thenar motor unit number (MUNE), estimated using the adapted multiple point stimulation method, and age in: 23 healthy subjects (A); and in the 19 subjects younger than 60 years $(B)$.

\section{DISCUSSION}

As the validity of $\mathrm{CV}$ data depends on the assumptions underlying the method used to estimate them, these will be discussed first.

Are FMUP CVs Really Representative of Motor Unit CV? Kimura's formula ${ }^{37}$ for CV calculation is not devoid of potential errors. The most important involves slow-conducting motor units in which orthodromic distal latency is longer than the onset of the $\mathrm{M}$ response, introducing a central latency overestimation. This error should be particularly significant in neuropathies with increased temporal dispersion of the latencies of motor units contributing to the M response. In healthy subjects, this bias is likely to be of minor importance. ${ }^{10}$ Moreover, this error is eliminated in trials in which the same motor unit is in-

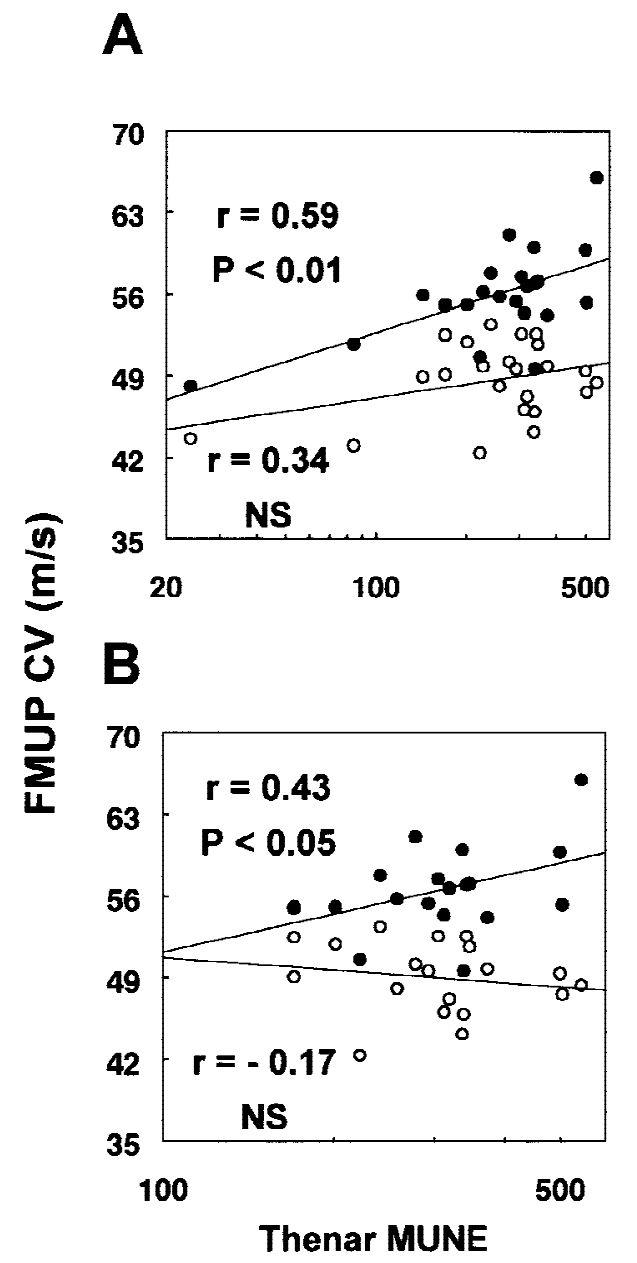

FIGURE 6. Relationship between maximal (dots) and minimal (circles) single thenar motor unit F-wave conduction velocity (FMUP CV) and thenar motor unit number (MUNE), estimated using the adapted multiple point stimulation method in: 23 healthy subjects (A); and in the 19 subjects younger than 60 years (B). 
volved in early and late motor responses (Fig. 1). Finally, minor errors might result from distance measurements between the site of stimulation at the wrist and the C-7 spinous process, or from small fluctuations of the 1-ms central turnaround time required for reactivation of the motoneuron. ${ }^{24}$

Is There a Motor Unit Selection Bias when Using the FMUP Method? Some investigators have suggested a selective activation bias toward the fastest conducting motor units in the $\mathrm{F}$ response. ${ }^{26-29,48,52}$ Fisher $^{26}$ argued that, in normal subjects, the mean latency range for $10 \mathrm{~F}$ responses was not larger than $15 \%$ of the minimal $\mathrm{F}$ latency, whereas for $\alpha$-motoneurons the smallest axonal diameters and CVs were about half those of the largest ones. ${ }^{5,23}$ In addition, Fisher $^{29}$ proposed that Renshaw-cell activation favors the selective discharge of the larger motoneurons in F waves. Renshaw cells would be activated by antidromic motor discharge of the more rapidly conducting motor units and would inhibit only the more slowly conducting motor units. However, Renshawcell inhibition requires discharge of $20-40 \%{ }^{14}$ of the motoneuron pool and this usually did not occur under our stimulation conditions.

Other investigators do not favor a selective activation of motor units in the $\mathrm{F}$ response. Schiller and Stålberg, ${ }^{51}$ using SFEMG, Kimura et al., ${ }^{38}$ using a collision technique, and Komori et al., ${ }^{40}$ in a FMUP study, indicated that all motor units showed occasional $\mathrm{F}$ responses regardless of their size or latency. Moreover, previous data did not indicate significant differences between FMUP persistence and the level of stimulus intensity. ${ }^{4,20}$

In a previous study, we systematically compared the AMPS and F-response techniques in 54 healthy subjects. MUNEs and average S-MUAP sizes, derived by both techniques, were significantly correlated ( $P$ $<0.001) .{ }^{57,58}$ Furthermore, the above reported results of CV distribution are comparable to those reported using either a similar ${ }^{20}$ or completely different technique. ${ }^{19,32,42}$ For all these reasons, we believe that the FMUP technique avoids any significant selection bias toward motor units of a particular CV. Moreover, 10 FMUPs may be considered a sufficiently large sample size to study the CV distribution of median motor nerve fibers.

CV Data Interpretation. In the present study, a statistically significant progressive decrease of motor CVs, calculated from all individual FMUPs evoked in the 23 healthy subjects, was shown with increasing age (Fig. 2). This result confirms previous data about motor CV changes with aging. ${ }^{21,47,50}$ When the CV of the fastest motor units (maximal CVs) and slowest motor units (minimal CVs) were considered separately in each subject, the age-related CV slowing was not uniform (Fig. 3A). The curve slope was steeper between maximal FMUP CV and age than between minimal FMUP CV and age. From a statistical point of view, maximal FMUP CV was significantly correlated with age, whereas no correlation was found between minimal FMUP CV and age (Fig. 3A). The individual FMUP CV dispersion study also suggested a nonuniform age-related motor CV change in all nerve fibers. Indeed, a statistically significant progressive decrease was found between individual FMUP CV dispersion and age that might result from a more pronounced slowing of maximal CVs (Fig. 4). These results are not in agreement with some previous data in the literature. Thus, Arasaki et al., ${ }^{2}$ using a computerized collision method, and later Doherty et al., ${ }^{20}$ using an F-response technique, have suggested that uniform slowing of motor axon CVs of all (fast and slow) nerve fibers occurs with age.

Three physiological mechanisms may be responsible for the observed age-related motor CV changes: (a) internodal length shortening ${ }^{3,22,33,41}$ induced by either remyelination after segmental demyelination or axonal regeneration; (b) reduction in axonal diameter $^{45}$ affecting either all motor fibers or motor axons following regeneration; and (c) myelinated fiber loss.

The present study demonstrates, in healthy subjects, a statistically significant and progressive decrease of thenar MUNE with aging (Fig. 5). From the predicted values, the calculated mean loss of motor units between the ages of 20-90 years was $80 \%$; it was $60 \%$ when the 4 eldest subjects were removed from the study, indicating a possible accelerated motor unit loss after the age of 60 years (Fig. 5B). To understand the possible role of motor unit loss in $\mathrm{CV}$ changes in healthy subjects, similar findings in patients are relevant. Thus, the motor CV slowing observed in advanced motor neuronopathies is usually attributed to a loss of large myelinated fibers. ${ }^{18,46}$ In particular, in patients with amyotrophic lateral sclerosis, a $30 \%$ reduction in motor CV below established normal values remains compatible with lower motoneuron degeneration if the amplitude of the compound action potential is greater than $10 \%$ of normal. ${ }^{6,18}$ In healthy subjects, a $80 \%$ motor unit loss in seven decades should induce similar CV changes. The statistically significant correlation between maximal FMUP CV and thenar MUNE (Fig. $6 \mathrm{~A})$ is indicative of such a possible mechanism. To account for the motor unit loss, three possibilities can be considered theoretically: (a) prominent loss of the largest and fastest conducting motor units; (b) 
random motor unit loss; and (c) prominent loss of the smallest and slowest conducting motor units.

The first hypothesis, a prominent loss of the largest and fastest conducting motor units, is best supported by our data. In fact, maximal FMUP CV was significantly correlated with age and MUNE, whereas minimal FMUP CV was neither significantly correlated with age nor with MUNE (Figs. 3A and 6A). These correlations were not heavily dependent on the results for the 2 eldest individuals, as indicated by Figures $3 \mathrm{~B}$ and $6 \mathrm{~B}$, in which results from the 19 subjects younger than 60 years were analyzed. The literature also provides arguments in favor of a prominent loss of the fastest and largest motor units with aging. Kanda and Hashizume, ${ }^{35}$ studying rat medial gastrocnemius muscles, found different CV changes with age in different motor unit types. Type $\mathrm{F}$ motor units showed significantly greater reductions in CV than type S. Burke ${ }^{11-13}$ established that type $\mathrm{F}$ motor units are fast-conducting and type $\mathrm{S}$ slow-conducting. Furthermore, most animal and human studies of aging effects have shown greater losses of the largest $\alpha$-motoneurons, and their corresponding myelinated axons, than of smaller motoneurons. ${ }^{1,31,39,61}$ Finally, age-related axonal damage, for example, from vascular changes or possible subclinical peripheral or cervical root entrapment, is also known to induce preferential loss of the largest and fastest-conducting motor fibers. ${ }^{8,30,43}$

The two other possibilities, random motor unit loss and prominent loss of the smallest and slowest motor units, are not in agreement with results from this study or the literature. Thus, progressive loss of the slowest conducting motor units should induce a minimal CV increase, and this was never observed. However, a minimal increase in CV may have been cancelled by a more direct mechanism slowing CV, such as internodal length shortening or reduction in axonal diameter. For example, if motor axons demyelinate, their CV may progressively decrease until the critical threshold of nonconductability is reached. Consequently, even the formerly fast-conducting axons may slowly drift down the axonal CV spectrum prior to dropping out entirely. This population of slowing (formerly fast) axons could, therefore, effectively mask the progressive loss of slow-conducting units. However, data from the literature ${ }^{3,33,41,56}$ do not indicate that these mechanisms play a noticeable role in the age-related changes of peripheral motor $\mathrm{CV}$. Internodal length shortening is only infrequently observed in patients over 60 years. ${ }^{33,41,56} \mathrm{Vi}$ tal et al., ${ }^{56}$ in a morphological study of 46 subjects (whose ages ranged from 70 to 95 years), reported that segmental demyelination was sparse in 26 cases and absent in 20 cases. Finally, a reduction in axonal diameter affecting all motor fibers, as proposed by Mittal and Logmani, ${ }^{45}$ on the basis of an increase in the number of small diameter fibers and a reduction in mean fiber diameter, remains questionable. In fact, the increase in small diameter fibers might be due to clusters of regenerating myelinated fibers, whereas an age-related large fiber loss might induce a reduction in mean fiber diameter.

In summary, we propose that there is a progressive decline in the number of largest and thus fastestconducting motor units throughout adult life and that this is responsible for most age-related changes of peripheral motor $\mathrm{CV}$, namely the continuous maximal CV slowing with aging.

The authors thank P. Gérard for her valuable technical assistance.

\section{REFERENCES}

1. Ansved T, Larson L. Quantitative and qualitative morphological properties of the soleus motor nerve and the L5 ventral root in young and old rats. J Neurol Sci 1990;96:269-282.

2. Arasaki K, Iijima M, Nakanishi T. Normal maximal and minimal motor nerve conduction velocities in adults determined by a collision method. Muscle Nerve 1991;14:647-653.

3. Arnold N, Harriman DGF. The incidence of abnormality in control human peripheral nerves studied by single axon dissection. J Neurol Neurosurg Psychiatry 1970;33:55-61.

4. Bergmans J. Physiological observation of single human nerve fibres. In: Desmedt JE, editor. New developments in electromyography and clinical neurophysiology. Vol. 2. Basel: Karger; 1973. p 89-127.

5. Borg J, Grimby L, Hannerz J. Axonal conduction velocity and voluntary discharge properties of individual short toe extensor motor units in man. J Physiol 1978;277:143-152.

6. Brooks BR. World Federation of Neurology criteria for the diagnosis of amyotrophic lateral sclerosis. J Neurol Sci 1994; 124:96-107.

7. Brown WF. A method for estimating the number of motor units in thenar muscles and the changes in motor unit count with ageing. J Neurol Neurosurg Psychiatry 1972;35:845-852.

8. Brown WF. The physiological and technical basis of electromyography. London: Butterworth; 1984. p 95-168.

9. Brown WF, Strong MJ, Snow R. Methods for estimating numbers of motor units in biceps-brachialis muscles and losses of motor units with aging. Muscle Nerve 1988;11:423-432.

10. Brown WF, Doherty TJ, Stashuk DW. Reservations on the motor unit number estimates based on the automated analysis of F-responses (a reply). Muscle Nerve 1995;18:1076-1078.

11. Burke RE. Motor unit types of cat triceps surae muscle. J Physiol 1967;193:141-160.

12. Burke RE, Levine DN, Zajac FE, Tsairis P, Engel WK. Mammalian motor units: physiological-histochemical correlation in three types in cat gastrocnemius. Science 1971;174:709-712.

13. Burke RE, Tsairis P, Levine DN, Zajac FE, Engel WK. Direct correlation of physiological and histochemical characteristics in motor units of cat triceps surae muscle In: Desmedt JE, editor. New developments in electromyography and clinical neurophysiology. Vol. 1. Basel: Karger; 1973. p 23-30.

14. Bussel B, Pierrot-Deseilligny E. Inhibition of human motoneurons, probably of Renshaw origin, elicited by an orthodromic motor discharge. J Physiol 1977;269:319-339.

15. Campbell MJ, McComas AJ, Petito F. Physiological changes in ageing muscles. J Neurol Neurosurg Psychiatry 1973;36: 174-182. 
16. Chroni E, Panayiotopoulos CP. F tacheodispersion: quantitative analysis of motor fiber conduction velocities in patients with polyneuropathy. Muscle Nerve 1993;16:1302-1309.

17. Chroni E, Panayiotopoulos CP. Reservations on the motor unit number estimates based on the automated analysis of F-responses. Muscle Nerve 1995;18:1074-1075.

18. Cornblath DR, Kuncl RW, Mellits ED, Quaskey SA, Clawson L, Pestronk A, Drachman DB. Nerve conduction studies in amyotrophic lateral sclerosis. Muscle Nerve 1992;15: 1111-1115.

19. Dengler R, Stein RB, Thomas CK. Axonal conduction velocity and force of single human motor units. Muscle Nerve 1988; 11:136-145.

20. Doherty TJ, Komori T, Stashuk DW, Kassam A, Brown WF. Physiological properties of single thenar motor units in the F-response of younger and older adults. Muscle Nerve 1994; 17:860-872.

21. Dorfman LJ, Bosley TM. Age-related changes in peripheral and central nerve conduction in man. Neurology 1979;29: 38-44.

22. Dyck PJ. Pathological alterations of the peripheral nervous system of man. In: Dyck PJ, Thomas PK, Lambert EH, editors. Peripheral neuropathy. Philadelphia: Saunders; 1975. p 296.

23. Dyck PJ, Jedrzcejowska H, Karnes J, Kawamura Y, Low PA, O'Brien PC, Offord K, Ohnishi A, Ohta M, Pollor KM, Stevens JC. Reconstruction of motor, sensory and autonomic neurons based on morphometric study of sampled levels. Muscle Nerve 1979;2:399-405.

24. Eccles JC. The central action of antidromic impulses in motor nerve fibers. Pflüger's Arch 1995;260:385-415.

25. Feasby TE, Brown WF. Variation of motor unit size in the human extensor digitorum brevis and thenar muscles. J Neurol Neurosurg Psychiatry 1974;37:916-926.

26. Fisher MA. F response latency determination. Muscle Nerve 1982;5:730-734.

27. Fisher MA. F Waves. Muscle Nerve 1985;8:71-72.

28. Fisher MA. Evidence for selective activation of faster conducting motor fibers in F waves. Muscle Nerve 1988;11:983.

29. Fisher MA. AAEM minimonograph \#13: $\mathrm{H}$ reflexes and $\mathrm{F}$ waves: physiology and clinical indications. Muscle Nerve 1992; 15:1223-1333.

30. Fowler TJ, Danta G, Gilliatt RW. Recovery of nerve conduction after a pneumatic tourniquet : observations on the hindlimb of the baboon. J Neurol Neurosurg Psychiatry 1972; 25: 638-647.

31. Hashizume K, Kanda K, Burke RE. Medial gastrocnemius motor nucleus in the rat: age-related changes in the number and size of motoneurons. J Comp Neurol 1988;269:425-430.

32. Ingram DA, Davis GR, Swash M. Motor nerve conduction velocity distributions in man: results of a new computer-based collision technique. Electroencephalogr Clin Neurophysiol 1987;66:235-243.

33. Jacobs JM, Love S. Qualitative and quantitative morphology of human sural nerve at different ages. Brain 1985;108:897-924.

34. Jušić A, Baraba R, Bogunović A. H-reflex and F-wave potentials in leg and arm muscles. Electromyogr Clin Neurophysiol 1995;35:471-478.

35. Kanda K, Hashizume K. Changes in properties of the medial gastrocnemius motor units in aging rats. J Neurophysiol 1989; 61:737-746.

36. Kawamura Y, O'Brien P, Okazaki H, Dyck PJ. Lumbar motoneurons of man II: the number and diameter distribution of large- and intermediate-diameter cytons in "motoneuron columns" of spinal cord of man. J Neuropathol Exper Neurol 1977;36:861-870.

37. Kimura J. F-wave velocity in the central segment of the median and ulnar nerves. A study in normal subjects and in patients with Charcot-Marie-Tooth disease. Neurology 1974; 24:539-546.
38. Kimura J, Yanagisawa H, Yamada T, Mitsudome A, Sasaki H, Kimura A. Is the $\mathrm{F}$ wave elicited in a select group of motoneurons? Muscle Nerve 1984;7:392-399.

39. Knox CA, Kokmen E, Dyck PJ. Morphometric alteration of rat myelinated fibers with aging. J Neuropathol Exp Neurol 1989; 48:119-139.

40. Komori T, Watson BV, Brown WF. Characteristics of single 'F' motor units at different stimulus intensities. Muscle Nerve $1991 ; 14: 875$.

41. Lascelles RG, Thomas PK. Changes due to age in internodal length in the sural nerve in man. J Neurol Neurosurg Psychiatry 1966;29:40-44.

42. Lee RG, Ashby P, White DG, Aguayo AJ. Analysis of motor conduction velocity in the human median nerve by computer simulation of compound muscle action potentials. Electroencephalogr Clin Neurophysiol 1975;39:225-237.

43. Magladery JW, McDougal DB, Stoll J. Electrophysiological studies of nerve and reflex activity in normal man. II. The effects of peripheral ischemia. Bull Johns Hopkins Hosp 1950;86:291-312.

44. McComas AJ. Neuromuscular function and disorders. London: Butterworths, 1977.

45. Mittal KR, Logmani FH. Age-related reductions in 8th cervical ventral nerve root myelinated fiber diameters and numbers in man. J Gerontol 1987;42:8-10.

46. Nakanishi T, Mitsuyuki T, Arasaki K. Maximal and minimal motor nerve conduction velocities in amyotrophic lateral sclerosis. Neurology 1989;39:580-583.

47. Norris AH, Shock NW, Wagman IH. Age changes in the maximum conduction velocity of motor fibers of human ulnar nerves. J Appl Physiol 1953;5:589-593.

48. Panayiotopoulos CP. F-chronodispersion: a new electrophysiologic method. Muscle Nerve 1979;2:68-72.

49. Panizza M, Nilsson J, Hallett M. Optimal stimulus duration for H reflex. Muscle Nerve 1989;12:576-579.

50. Schaumburg HH, Spencer PS, Ochoa J. The aging human peripheral nervous system. In: Katzman R, Terry RD, editors. The neurology of aging. Philadelphia: FA Davis; 1983. p 111-122.

51. Schiller HH, Stålberg E. F responses studied with single fibre EMG in normal subjects and spastic patients. J Neurol Neurosurg Psychiatry 1978;41:45-53.

52. Shahani BT, McLeod WN, Bertics GM. Minimal F response latencies as a measure of conduction in largest diameter alpha motor axons. Neurology 1987;37(suppl 1):114.

53. Sica REP, McComas AJ, Upton ARM, Longmire D. Motor unit estimations in small muscles of the hand. J Neurol Neurosurg Psychiatry 1974;37:55-67.

54. Tohgi H, Tsukagoshi H, Toyokura Y. Quantitative changes with age in normal sural nerves. Acta Neuropathol 1977;38: 213-222.

55. Tomlinson BE, Irving D. The numbers of limb motor neurons in the human lumbosacral cord throughout life. J Neurol Sci 1977;34:213-219.

56. Vital A, Vital C, Rigal B, Decamps A, Emeriau JP, Galley P. Morphological study of the aging human peripheral nerve. Clin Neuropathol 1990;9:10-15.

57. Wang FC. Nombre et taille des unités motrices de l'éminence thénar. In: Soichot P, editor. L'Electrodiagnostic en 1996: mises au point. Dijon: S'Print; 1996. p 205-216.

58. Wang FC, Delwaide PJ. Number and relative size of thenar motor units estimated by an adapted multiple point stimulation method. Muscle Nerve 1995;18:969-979.

59. Wang FC, Delwaide PJ. Single motor unit H-reflexes recorded in thenar muscles at rest. Muscle Nerve 1999;22:291-292.

60. Zhang C, Goto N, Zhou M. Morphometric analyses and aging process of nerve fibers in the human spinal posterior funiculus. Okajimas Folia Anat Jpn 1995;72:259-264.

61. Zhang C, Goto N, Suzuki M, Ke M. Age-related reductions in number and size of anterior horn cells at C6 level of the human spinal cord. Okajimas Folia Anat Jpn 1996; 73: 171-177. 